\title{
Reflexões sobre ética, cinema e educação: um estudo de caso a partir do filme "O caso dos Irmãos Naves" (1967) de Luís Sérgio Person
}

\author{
Alexandre Matias Silva ${ }^{11}$ \\ Danilo Rocha ${ }^{12}$
}

\begin{abstract}
Resumo: O presente artigo baseia-se numa reflexão sobre o cinema, a ética e a educação, utilizando como estudo de caso a obra de Luís Sérgio Person, "O Caso dos Irmãos Naves", de 1967. Buscou-se uma análise mais detalhada sobre a ética e a banalidade do mal, reflexão esta última, de Hannah Arendt. A necessidade de discutir ambos os temas dentro de uma perspectiva dialética em sala de aula se faz importante em meio à crise ética e à maldade diária, vivenciadas nos tempos atuais. Diante disso, o cinema pode servir como um instrumento para mediação e construção do conhecimento. O filme "O Caso dos Irmãos Naves" é um bom exemplo de como o cinema nacional pode ser útil para discutir temáticas mais complexas, como a ética e a banalidade do mal, podendo ser utilizado como fator mobilizador da reflexão filosófica em sala de aula.
\end{abstract}

Palavras-chave: Educação, ética e cinema.

\section{Reflections about ethic, cinema and education: a case study from the film "The Case of the Brothers Naves" (1967) by Luis Sérgio Person}

\begin{abstract}
The present article starts from the establishment of a reflection on the cinema the ethics and the education using as a case study the work of Luis Sérgio Person, "The Case of the Brothers Naves" of 1967, to reflect on the ethics and the banality of the evil, the latter, Hannah Arendt's reflection. Faced with the ethical crisis and daily evil seen in our times, it is necessary to discuss both themes within a dialectical perspective in the classroom, where the cinema can serve as an instrument for mediation and construction of knowledge. The film "The Case of the Brothers Naves" is a good example of how national cinema can be useful to discuss more complex themes, such as ethics and banality of evil, and can be used as a mobilizing factor of philosophical reflection in the classroom.
\end{abstract}

Keywords: Education, Ethics and cinema.

\section{Introdução}

O cinema não nos permite fazer economia do pensamento [...] O cinema oferece uma ajuda da imaginação a nosso entendimento. Ele nos propõe ver

\footnotetext{
${ }^{11}$ Possui graduação em ciências jurídicas e sociais (1998) e licenciatura em filosofia (2017), mestrado em Filosofia pela Universidade São Judas Tadeu (2014). Atualmente é consultor jurídico do Centro de Orientação Fiscal e professor na Faculdade de Tecnologia Carlos Drummond de Andrade - SP. Possui experiência na docência no ensino superior nas áreas de ciências sociais e humanas. Atualmente é pesquisador CNPq do GECEF-CEUCLAR- Grupo de Estudos em Cinema e Ensino de Filosofia do Centro Universitário Claretiano. E-mail: professormatias@bol.com.br

${ }^{12}$ Licenciado em Filosofia e Licenciando em Letras - Língua Portuguesa. - (Pós-Graduando em Ciências da Religião - Especialização Teológica). Atualmente é - (Professor de Filosofia no Ensino Médio) -, Pesquisador CNPq do GECEF-CEUCLAR- Grupo de Estudos em Cinema e Ensino de Filosofia do Centro Universitário Claretiano. E-mail: professordanilorocha@gmail.com
} 
com os olhos do corpo o que não deveria ser visível senão com os olhos do espírito [...] Ollivier Pourriol

O primeiro artigo que trata da temática educacional da constituição Federal de 1988, explica: “Art. 205. A educação, direito de todos e dever do estado e da família, será promovida e incentivada com a colaboração da sociedade, visando ao pleno desenvolvimento da pessoa, seu preparo para o exercício da cidadania e sua qualificação para o trabalho." (BRASIL, 1988, p. 121).

Já no capítulo terceiro intitulado Da Educação, Da Cultura e do Desporto, o primeiro artigo indica a direção que a educação e os educadores devem seguir: uma proposta educacional voltada para o trabalho, mas também para a cidadania.

Mas afinal, o que é cidadania? A cidadania se define como "condição de cidadão". Por sua vez, o cidadão é um indivíduo no gozo dos direitos civis e políticos de um estado. Dessa forma, observa-se que um dos papéis da educação é para preparar o indivíduo para o reconhecimento dos seus direitos.

De acordo com as Diretrizes Nacionais da Educação, observa-se que um dos papéis da escola é preparar o indivíduo frente aos direitos que lhe assiste:

“A educação é um instrumento imprescindível para que o indivíduo possa reconhecer a si próprio como agente ativo na modificação da mentalidade de seu grupo e ser promotor dos ideais humanos que sustentam o movimento a favor da paz e dos direitos humanos. ” (BRASIL, 2013, p. 56)

"O mesmo documento ainda alerta:

O direito à educação não se resume ao acesso à escola, pois ele não será vivenciado plenamente se a escola não der ao indivíduo informações, conhecimentos e domínio de técnicas imprescindíveis à compreensão do mundo que o rodeia, desenvolvendo nele o senso crítico que o levará a uma ação transformadora da sociedade. (BRASIL, 2013, p. 51)

As instituições educacionais devem procurar instigar as capacidades críticas de seus alunos e evitar estratégias de ensino onde a mecânica, a artificialidade, e as ações não reflexivas imperam. Saviani (2010), aborda em um de seus artigos o assunto das atitudes mecânicas, tomadas, muitas vezes, por parte da educação brasileira:

[...] Ações se tornam mecânicas, automáticas, rompendo o movimento dialético ação-reflexão-ação, que é condição sine qua non da educação sistematizada e, portanto, da prática educativa própria do sistema educacional. (SAVIANI, 2010, p. 388) 
É necessário que o ensino se distancie definitivamente de práticas que estimulem comportamentos mecânicos e não reflexivos. As artes são uma fonte rica para ações reflexivas: um local onde o sentimento, o pensamento e a criatividade estão em abundância, um local fértil para "olhares" críticos.

O cinema é uma arte e, como parte dela, também possui as características supracitadas. No Brasil, a Lei de Diretrizes e Bases da Educação Nacional (1996, p. 20) recomenda no artigo vinte e seis (26) inciso (§) oitavo $\left(8^{\circ}\right)$, o uso obrigatório de filmes nacionais nas escolas, estipulando até um mínimo de 2 horas/mensais de exibição em sala de aula:

A exibição de filmes de produção nacional constituirá componente curricular complementar integrado à proposta pedagógica da escola, sendo a sua exibição obrigatória por, no mínimo, 2 (duas) horas mensais. (BRASIL, 1996, p. 20)

No ano de 1967, durante o período de ditadura militar, foi lançado um filme nacional com cenas fortes e mensagens profundas e marcantes: O Caso dos irmãos Naves, realizado pelo cineasta Luis Sérgio Person.

Jean-Claude Bernardet, na obra O Caso dos Irmãos Naves: Chifre em Cabeça de Cavalo (2004), comenta sobre o filme dirigido por Luis Sérgio Person. Bernadet teve participação direta em sua elaboração, relatando que o filme foi baseado em histórias verídicas de um caso ocorrido no interior de Minas Gerais e que despertou a atenção e revolta no cineasta Luis Sérgio Person, três décadas depois do ocorrido.

$\mathrm{Na}$ década de trinta, década inclusive que nasceu Luis Sérgio Person, os irmãos Naves foram, sem provas, culpados por um crime, torturados brutalmente e condenados por algo que nem sequer aconteceu. Segundo Bernardet, o cineasta Person foi até seu encontro certo dia com um papel velho e amarelado nas mãos, o qual abordava uma matéria sobre o caso Naves. Revoltado com o ocorrido, a intenção de Person era produzir um filme baseado no acontecimento, tornando públicas aquela injustiça e barbárie e, ao mesmo tempo, alertar-nos para os direitos civis.

Por sorte o filme, O Caso dos Irmãos Naves, em 1967, não teve problemas com a censura imposta pelos militares à época, e a mensagem que o diretor Person queria transmitir foi veiculada de forma integral, sendo potencialmente reflexiva e instigadora. Segundo Reina (2016, p. 80) "os bons filmes são construídos a partir desta 
perspectiva. Os realizadores que tomam o filme não apenas como mero entretenimento, mas como forma de pensamento, fazem obras primas. "

O filme de Person trata de diversos temas polêmicos, como o abuso da autoridade, a tortura, a insensibilidade, o espaço para erros e injustiça no poder judiciário, bem como nos faz refletir sobre as condutas humanas. E isso não é exatamente a definição mais usual de ética? A ética não seria uma reflexão da moral (conduta)? Segundo Valls (1994, p. 07) “A ética é daquelas coisas que todo mundo sabe o que são, mas que não são fáceis de explicar, quando alguém pergunta". Para Cortina e Martinez (2005, p. 03):

\begin{abstract}
A palavra ética vem do grego ethos, originalmente tinha o sentido de 'morada', 'lugar em que se vive' e posteriormente significou ‘caráter', ‘modo de ser' que se vai adquirindo durante a vida... Ética refere-se à filosofia moral, isto é, ao saber que reflete a dimensão da ação humana. (CORTINA, MARTINEZ, 2005, p. 03)
\end{abstract}

Faz-se importante comentar que a ética é realizada somente pelo homem; apenas o homem, dentre todos os animais existentes no planeta, tem a capacidade de ser ético ou não o ser. A ética foi alvo de interesse em todos os períodos da história da humanidade, do período clássico até a contemporaneidade e num futuro próximo, a discussão em torno do tema tende a se distender de forma constante.

Dessa maneira, justifica-se a importância de abordar o ensino da ética em sala de aula, através da arte, possibilitando a exibição de obras do cinema nacional, como o filme O Caso dos Irmãos Naves (1967). A proposta deste estudo é, em primeiro lugar, problematizar o tema da ética por meio do recurso fílmico, como proposta educativa. Em segundo plano, propõe-se uma reflexão acerca do pensamento de Hannah Arendt, mais especificamente seu conceito de banalidade do mal dentro da perspectiva filosófica, aplicado aos eventos narrados no filme de Luiz Sérgio Person.

\title{
O cinema brasileiro: Breve história
}

Desde a primeira exibição pública de um filme, em 28 de dezembro de $1895 \mathrm{em}$ Paris, fruto de intenso trabalho dos irmãos Lumière, o cinema evoluiu tanto no aspecto técnico como na sua relação com o público que consome e o produz. A força do cinema está na poderosa combinação do som e imagem, além do forte impacto que o recurso fílmico provoca no expectador, permitindo que a ilusão e a realidade se confundam. 
Importante fator que confirma a força do cinema e o consolida como arte, foi lembrada por Jean-Claude Bernardet (2004, p.23), quando este se refere a possibilidade de fácil reprodução do cinema. A forte difusão do cinema, em comparação com outras manifestações artísticas, consolidou sua posição como "a sétima arte".

Esse processo abriu as portas do cinema, de Paris para o mundo. Assim, apesar de nascer na Europa ainda no século XIX, a produção cinematográfica se expande para outros países que também se consolidam como importantes centros de produção.

Atualmente, o cinema norte-americano tem se consolidado por sua força comercial e tecnológica em suas superproduções. Contudo, outros países também construíram uma interessante história cinematográfica que transcendia os aspectos tecnológicos. Apesar de toda força que possuí o cinema norte-americano, a história do cinema não pode desprezar grandes obras do antigo cinema soviético iniciada nos anos 1920 e sua valorização da montagem como recurso fílmico, como nos lembra Bernadet (2004, p.48).

O cinema alemão nos anos 1920 e 1930 foi fortemente influenciado pelas artes e literatura (Bernardet, 2004, p. 53), fazendo assim a ligação entre a produção fílmica e a literária. Na Itália, o neo-realismo dos anos 1940 procurou retratar o cotidiano da sociedade italiana no pós-guerra, em toda sua simplicidade, inclusive utilizando atores amadores nestas produções. Já o cinema francês dos anos 1950 traz uma perspectiva existencialista, que pouco retrata as questões sociais.

Por fim, a África também despontou com um cinema feito de poucos recursos, porém com disposição, utilizando recursos técnicos importados. Vale também destacar os cinemas argentino e o indiano e suas diversas produções.

\section{Cinema brasileiro}

O cinema brasileiro ao longo dos anos granjeou seu devido reconhecimento internamente, bem como internacionalmente, como faz provar os mais diversos prêmios internacionais. Isto se deve, em certa medida, ao movimento denominado "cinema novo", na década de 60, que de certa forma procurou retratar o Brasil. Obras como Vidas Secas, de Nelson Pereira dos Santos em 1964, Deus e Diabo na Terra do sol, de Glauber Rocha em 1964, e Os Fuzis, de Ruy Guerra em 1964, foram reconhecidas e imprimem um forte contexto social e político brasileiros. 
No Brasil o cinema se desenvolve progressivamente ao longo das décadas. Há registros apontando o início do cinema no Brasil em 08 de julho de 1896 na cidade do Rio de Janeiro, apenas cerca de sete meses após a primeira projeção feita pelos irmãos Lumière em 28 de dezembro de 1985, como nos lembra Vasconcelos e Matos (2012). Apesar de certas divergências sobre o tema, é possível pensar que Afonso Segreto tenha produzido o primeiro filme realizado no Brasil, uma tomada da Baia de Guanabara.

É importante destacar que a produção fílmica no Brasil na virada do século XIX para o XX foi intensa. Contudo o avanço do cinema internacional, sobretudo o cinema produzido na Europa e América do Norte, acabou por refletir na produção de filmes nacionais, freando o ciclo evolutivo no início dos anos 1910, e que seria agravado com a crise econômica decorrente da Primeira Guerra Mundial, conforme lembram Vasconcelos e Matos (2012).

O cinema brasileiro ganhou espaço durante o século XX, cresceu e certamente teve seu lugar de destaque. Dentre as escolas do cinema brasileiro destacaremos uma em especial, conhecida como "Cinema Novo" e que representou um período de extrema importância na história do cinema nacional.

Jovens vanguardistas, que vieram a se tornar importantes nomes desta nova escola, como Cacá Diegues, Glauber Rocha e Leon Hirszman, mergulhariam nessa importante experiência chamada Cinema Novo. Uma das características marcantes desta escola foi sua abordagem predominantemente voltada para uma perspectiva histórica do Brasil, o que indica uma tentativa de compreender o país e seu percurso.

Devido a alguns aspectos similares, é possível pensar que o cinema italiano neorrealista tenha inspirado esses jovens cineastas brasileiros no final dos anos 50, uma vez que o Cinema Novo, de certa maneira, tentou mostrar um Brasil até então desconhecido para o brasileiro.

"Uma câmara na mão e uma ideia na cabeça", era o lema que inspirou os cinemanovistas e suas produções de baixo orçamento, mas de forte impacto (artístico, filosófico?), uma vez que deixavam de lado as produções musicais ou comédias tão comuns à época, para produzir um cinema que abordava temas mais complexos como a miséria, o coronelismo, o misticismo e o homem do Nordeste.

O Cinema Novo também foi também um cinema de teor político-social, produzido em um contexto politicamente rico, entre os governos Jânio Quadros até o início da ditadura militar (1964 - 1970). Nesta perspectiva, destacamos o filme Terra em transe (1967), de Glauber Rocha, e Os Herdeiros (1970), de Cacá Diegues. 
De forma geral, encontramos nos filmes personagens aparentemente caricaturados, buscando representar importantes aspectos na cultura e na história brasileira, como o negro, o índio, o herói, o homem da seca e a mulher sensual, como observado por Maria do Socorro Carvalho (2014).

O Cinema Novo, dentro de sua proposta crítica, buscou mostrar um Brasil não ufanista do período Vargas e JK, permitindo que o público pudesse refletir para além dos grandes centros.

Como muitos setores do mundo acadêmico, cultural e político, o cinema brasileiro, em especial o Cinema Novo, foi reprimido e censurado pelo golpe militar, prejudicando sua continuidade e o trabalho dos cineastas. Como bem salientou Maria do Socorro Carvalho (2014): os militares não permitiram que os cineastas continuassem a discutir o Brasil com a radicalidade necessária que vinha sendo.

Na prática, não há uma paralisação das produções, mas um refluxo que provocou uma readequação por parte dos cineastas, que ainda tentaram manter-se firmes na perspectiva do Cinema Novo, apesar das limitações impostas pelo regime. Não obstante, é possível perceber um verdadeiro esforço para se manter as produções ligadas ao movimento do Cinema Novo nos "Pós 64", ainda que a temática tenha se alterado sutilmente, como se percebe na produção Garota de Ipanema de 1967, filmado já em cores.

\section{O cinema contemporâneo}

Em um contexto contemporâneo, nos reportaremos ao período subsequente à década de 1990. O fechamento da Embrafilme demonstrava uma tentativa do governo federal, capitaneado na época por Fernando Collor de Mello, de dar um viés mercantil e profundamente liberal ao cinema brasileiro, tornando-o um negócio como outro qualquer, regido pelas leis de mercado, típico da mentalidade neoliberal ainda em germe no Brasil. Tal política representou um forte golpe na produção cinematográfica brasileira, que ainda procurava se recuperar das dificuldades impostas pelo regime militar, em especial pelos censores. Este cenário acabou acarretando uma queda brutal na produção de filmes nesse período.

Com o fim do governo Collor, o cinema brasileiro ganha novos incentivos governamentais e as produções começam a aumentar em número. 
Como afirma Luiz Zanin Oricchio (2016), o longa Carlota Joaquina pode ser considerado um marco dessa nova fase de retomada do cinema nacional. Uma nova fase de consolidação do cinema é apontada por Orrichio (2016) que afirma serem produzidos 167 longas-metragens, entre 1995 e 2001.

Nos últimos anos o cinema brasileiro se aproximou do público com produções que foram bem recepcionadas, como Central do Brasil, Carandiru, Cidade de Deus, O Auto da Compadecida e Se eu fosse você. Por outro lado, também nos deparamos com obras de forte apelo crítico, como do diretor paranaense Sérgio Bianchi.

Os filmes disponibilizados no Brasil ao grande público consumidor de cinema ainda são permeados por obras comerciais, com roteiros de pouca complexidade e de fácil apelo. Nesse sentido Oricchio se vê pessimista:

\footnotetext{
Quando às considerações estéticas pode-se dizer que, em meio a pretensa "diversidade", prevalece, pelo contrário, uma produção bastante rotineira, do ponto de vista da linguagem cinematográfica. $\mathrm{O}$ constante desafio pelo mercado tende a conduzir a um tipo de expressão banal, que se aproxima da linguagem audiovisual dominante de ficção, que é a das novelas da TV Globo, um padrão naturalista, cômico ou melodramático já estabilizado pelo mercado. Sobra, portanto, pouco espaço para a inovação, a ousadia temática a pesquisa de linguagem, quer dizer, para aquilo que seria o exercício, de fato de uma diversidade ativa e não pró-forma ou mercadológica. (ORICCHIO, 2016, p. 155)
}

A partir da metade dos anos 1990, houve a retomada do cinema brasileiro, culminando com o desenvolvimento do cinema nacional em seus diversos aspectos estéticos. Embora tenhamos obras marcadamente comerciais, há um reconhecimento interno e internacional deste cinema, revelando uma enorme evolução técnica e o surgimento de uma geração de roteiristas e diretores competentes, além do reconhecimento de novos atores.

\section{Luiz Sérgio Person (1936 - 1976) - Perfil Biográfico}

Person soma trabalhos como ator, roteirista, diretor e produtor de cinema e atividades envolvendo televisão, teatro e publicidade. Apesar de ser um dos grandes representantes do cinema nacional, Person possui uma pequena produção realizada entre os anos de 1957 a 1974, em razão de sua acidental e precoce morte em 1976.

Em 1954, ingressa no curso de direito na Universidade de São Paulo, mas que não concluí. Entre 1961 e 1963, estuda Direção no Centro Sperimentale di 
Cinematografia (CSC) em Roma e, nesse período, produz curta metragens e atua como assistente de direção. Apesar de sua obra abarcar o período que vai da década de 1950 a 1970, é possível pensar que Person atinge o ponto culminante de sua carreira com a reconhecida obra São Paulo, Sociedade Anônima (1965), filme onde o personagem central remete à própria experiência de Person, quando se distância das artes para assumir a direção de uma empresa da família, antes de sua ida para Roma.

Também merece destaque em sua filmografia a direção de O Caso dos Irmãos Naves, de 1967. Além da direção, divide o roteiro com seu constante colaborador JeanClaude Bernardet. Mesmo com uma pequena filmografia, seu conteúdo foi reconhecido pelo público e pela crítica, sendo vencedor de importantes festivais nacionais como o Festival de Brasília, com O Caso dos Irmãos Naves (melhor roteiro), além do Festival de Gramado com a obra Cassey Jones, o magnífico sedutor, de 1972 (melhor diretor).

Recentemente o público teve a oportunidade de conhecer Person e sua obra, além de aspectos familiares depois do documentário dirigido por sua filha, Marina Person, intitulado Person, de 2007. A filmografia de Person, ainda que pouca extensa, constitui um rico acervo ao tratar de temas tão variados e importantes, contribuindo na problematização de questões éticas e na construção de uma educação através do cinema.

\section{Educação, cinema e ética}

O professor Leandro Karnal (2017, p. 94) descreve a forma com que os filósofos clássicos interpretam o conceito de "uma boa aula", e que até hoje é válida:

Há algo que valia na Academia de Platão ou no Liceu de Aristóteles e vale hoje, no século XXI: uma boa aula é aquela que faz pensar, provoca reflexão e traz, com isso, uma nova percepção das coisas. Uma boa aula atinge seu objetivo, seduz e instiga. (KARNAL, 2017, p. 94)

A inserção da tecnologia nas instituições escolares concretizou novas formas de se atingir o que se denominou como uma boa aula. Leandro Karnal (2017, p. 91) relata, em seu livro, o itinerário das tecnologias usada pelos professores, até a possibilidade de utilizar os filmes como recurso pedagógico:

Quando eu comecei a dar aulas, o mimeógrafo que utilizava álcool era um aparelho universal e todos aprendíamos a utilizá-lo para reproduzir textos e provas. Ao mesmo tempo, difundia-se o retroprojetor, aparelho que projetava transparências na parede. Chegou a ser tão utilizado que, dizia-se (talvez como piada) que alunos convidavam o retroprojetor para paraninfo nas 
formaturas. Havia sido quem mais tinha conversado com eles. Por anos, o retroprojetor de slides marcou sua presença e, a partir dos anos 1980, cresceu a utilização de filmes em videocassete com fins didáticos, quase ao mesmo tempo em que o xérox substituía o mimeógrafo. (KARNAL, 2017, p. 91)

Karnal (2017, p. 91) ainda enaltece que a novidade da tecnologia trouxe consigo a novidade da forma de aprender entre os jovens:

Há dois aspectos a considerar agora. Um foi a transformação do computador e da internet como recursos didáticos. Essa mudança é visível e importante. $\mathrm{O}$ outro, menos palpável, é a transformação na cabeça dos alunos e na maneira de aprender. Essa é mais importante ainda. (KARNAL, 2017, p. 91)

Por sua vez, Santos (2008, p. 07) comenta sobre a importância da mudança da instituição escolar frente a estas mudanças na tecnologia, onde "o contexto atual marcado por grandes evoluções na sociedade, principalmente de cunho científico e tecnológico, requer mudanças na escola, especialmente na atuação do professor."

Karnal (2017, p. 99) ainda fornece dicas para lidar com o "novo" discente, o aluno do século XXI: "Utilizar, sempre que possível, recursos sensoriais como imagens e música. Escolha bem, trabalhe o recurso e utilize com objetividade."

Reina (2016), reforça a ideia do audiovisual, abordando a compreensão de relacionar o seu uso com uma metodologia, e salienta o cuidado na utilização de recursos pedagógicos alternativos, como a utilização de filmes. O professor recomenda que não devem ser utilizados com muita frequência, pois fazer uso sempre de uma mesma ferramenta em sala de aula é pouco eficaz para o aprendizado. Ainda, Reina (2016, p. 102) fala sobre a capacidade do cinema. Esta arte, através da ficção, pode reinventar nossa própria realidade:

Quando afirmamos que o fato do cinema se basear na ficção não é argumento suficiente para classificarmos como não filosófico, isto refletirá em grande medida o conceito da transfiguração, pois ao criar a ficção o filme permite ao espectador uma experiência estética que vai além do fictício. Ao apropriar-se desta experiência o espectador não somente recria o real como o reinventa de sua maneira. Este processo de apropriação, criação e reinvenção, vem ao encontro do conceito de transfiguração. O cinema simula o real, mas ao apropriar-se desta simulação o espectador reinventa o próprio real, transfigurando-o, afastando-se da produção de um possível pensar filosófico representativo e aproximando-se de uma genuína experimentação da vida. (REINA, 2016, p. 102) 
Reina (2016) comenta sobre a possibilidade do cinema trabalhar com as emoções sobre elementos lógicos, sendo capaz de emocionar e ao mesmo tempo despertar pensamentos críticos através da razão.

De acordo com Santos (2008, p. 05): "Na atual instituição educacional não se admite mais currículos que não sejam críticos, que desafiem os alunos, que os levem a pensar, a refletir." (Santos, 2008, p. 09). Ainda complementa: “O professor precisa assumir seu papel de mediador de facilitador do processo, instigando os alunos a pensar, a refletir, a pesquisar, conduzindo-os para a construção do conhecimento. ”

Reina (2016, p.131) indica, assim, a possibilidade dos filmes de provocar pensamentos críticos e profundos:

Em uma prova escrita, por exemplo, diante de uma questão o aluno tem em vista o que "foi dito pelo professor" ou "o que está escrito em seu livro didático ou em seu caderno", nestes termos a reflexão é condicionada pelo próprio instrumento de avaliação e a nota é o símbolo máximo disto. $\mathrm{O}$ aluno não cria absolutamente nada, não descobre, não constrói, pois, a intenção é que ele apenas a reproduza um saber cristalizado por uma tradição dentro do conteúdo da disciplina. Quando o filme é utilizado como instrumento didático esta posição muda, pois o professor coloca o problema e o aluno deve obter as respostas a partir de sua compreensão do filme. Nestes termos não há um conhecimento cristalizado a ser lembrado, nem cânones a serem obedecidos, o aluno com desconfiança absoluta arrisca-se a fornecer uma resposta para o problema filosófico colocado diante das imagens do filme, ou seja, ele precisa construir uma opinião crítica sobre o assunto, não existe conhecimento, pois este será construído mediante o diálogo com o professor e os outros colegas após a exibição do filme. Porém, cabe ressaltar que a utilização do filme deve ser precedida de um rigoroso planejamento por parte do professor, do contrário todo o trabalho não surtirá o efeito desejado no que diz respeito à aprendizagem da filosofia por parte dos alunos. (REINA, 2016, p. 131)

Leandro Karnal (2017), também fala da possibilidade dos filmes como catalisadores para um pensar mais crítico:

Ir a um filme no final de semana, ou de vez em quando durante a semana, pode ser uma excelente opção de lazer. Temos a nossa disposição, boas comédias, excelentes filmes dramáticos, e também filmes românticos. No cinema você pode acompanhar uma história, emocionar-se com a música, com a fotografia, pode desenvolver pensamentos; pode passar uma hora e meia, duas; absorvido naquele espaço onde um diretor, um escritor, um grupo de atores, e outros profissionais; narra algo que dialoga conosco. Mas não veja um filme para passar o tempo, veja um filme que dialogue com seus valores, veja um filme que faça você repensar várias questões, aproveite um filme para que ele entre em sua consciência, para que concordando ou discordando, gostando ou não gostando, você consiga produzir naquele instante um passo adiante na sua visão de mundo. Todo filme deve transformar a sua cabeça, deve transformar a sua percepção, sendo divertido ou dramático, trágico ou cômico, um filme tem que produzir em mim uma 
capacidade de pensar mais, ele não pode ser um passa tempo, não devemos gastar o tempo porque o tempo não pode ser recuperado, devemos aproveitar o tempo do filme concentrado sem olhar no celular, sem conversar com outras pessoas para não atrapalhar, mas acima de tudo tentando captar ideias, uma cena, uma música, uma fala, que pode de agora em diante fazer parte do meu repertório e me tornar uma pessoa mais interessante. (KARNAL, 2017)

Os textos recém expostos corroboram para que o cinema seja visto como uma ferramenta possível de ser trabalhada em sala de aula, com temáticas mais profundas, como a ética. Isso permite que a ferramenta didática "cinema" seja um catalisador para pensamentos mais profundos, provocando reflexões e emergindo uma nova percepção nos alunos. E não seria esta a definição de uma boa aula, explicitada anteriormente por Karnal (2017).

O site Cabine Cultural (2015), traz uma definição filosófica de ética, "Do ponto de vista da Filosofia, a ética se dedica a pensar e refletir as ações humanas, bem como seus fundamentos. Ela reflete, portanto, sobre os valores e princípios morais de uma sociedade e seus grupos. " O site Cabine Cultural (2015) ainda traz uma importante contribuição do tema sobre ética no cinema:

\begin{abstract}
O cinema desde a sua origem vem sendo uma boa ferramenta para refletirmos sobre questões éticas e morais; lista com ótimos filmes. Ética no cinema, moral no cinema. Certamente você se deparou por muitas vezes com estes termos, sobretudo em sites de listas de filmes ou sites de filosofia. O fato é que é bastante compreensível o ser humano se interessar por questões que abordam seus costumes, seus princípios, suas ações, pois essas questões o definem enquanto homem. Há uma necessidade natural de sabermos e entendermos as nossas atitudes e mediarmos nossos acordos de convivência, e o cinema, mais que qualquer outra arte, soube explorar essa temática de nodo intenso. (CABINE CULTURAL, 2015)
\end{abstract}

Como descrito, o cinema trabalha, desde sua origem, com a temática ética e moral. Os redatores de Cabine Cultural montaram uma lista com os oito mais importantes filmes, segundo o site, que abordam ética e moral: Laranja Mecânica (EUA-1971), Crash, no Limite (EUA-2004), Quem somos nós? (EUA-2004), Ponto de Mutação (EUA-1990), Efeito Borboleta (EUA-2004), O mundo de Sofia (NOR1999), O Abutre (EUA-2014) e O Jardineiro Fiel (EUA-2005). Reina (2016) também cita outros filmes que nos faz refletir sobre as ações humanas, incluindo Além da Linha Vermelha (EUA-1998), Platoon (EUA-1986) e Nascido para Matar (EUA-1987).

Christofoletti (2003, p.32-33) fala de sua experiência do uso do cinema para tratar temas éticos: 
Logo nas primeiras aulas, distribuo uma lista de vinte sugestões de filmes para que os alunos assistam às fitas em sua casa. Em todas elas, algumas personagens se deparam com situações em que os valores éticos são colocados em xeque, suas condutas são avaliadas por terceiros ou suas ações podem interferir diretamente no rumo dos acontecimentos. A lista de filmes é acompanhada das instruções para o desenvolvimento de um trabalho a ser entregue no segundo bimestre da disciplina, quando a maior parte do conteúdo já tiver sido observada. O texto das orientações sobre trabalho é o que vem a seguir: Abaixo você tem algumas sugestões de filmes em vídeo, onde são discutidos aspectos e dilemas éticos envolvendo jornalistas. Em cada enredo, em cada história, sempre há peloi menos uma situação a ser refletida. Escolha um ou mais dos filmes sugeridos e faça um texto discutindo: Qual é o dilema ético em questão? Como agem as personagens nesta situação? Esta foi a melhor saída? E se fosse você? De que forma reagiria? Faria como a personagem? Assista o filme de forma diferente, prestando atenção não apenas á trama em si, mas também ao comportamento ético das personagens, e perceba a discussão que o filme está propondo. Faça uma análise aprofundada e um texto claro, coeso e coerente. (CHRISTOFOLETTI, 2003, p. 32-33)

Carneiro (2017) fala da possibilidade dos filmes em trazer uma mensagem de como devemos agir, podendo ser aceita ou não, através de uma reflexão:

O cinema traz mensagens éticas que, de certa forma, representam o comportamento que uma sociedade espera de seus integrantes. Podemos aceitar ou não a mensagem, refletir sobre ela e ver como se aplica à nossa vida... A decisão sobre como devemos viver é sempre nossa. (CARNEIRO, p. 2017)

Gedeon (2006), valendo-se das ideias de Paulo Freire, nos diz sobre a importância da educação na formação dos alunos, de suas condutas e costumes:

O ato de educar, no longo e infindável desenvolver da espécie humana, sempre foi um ato imbuído de responsabilidade e compromisso na preparação e formação dos indivíduos que compõe uma sociedade. As relações sociais entre indivíduos, adultos e crianças, promove a sustentabilidade das noções básicas para a reprodução de modos e normas fundamentais para a continuidade da vida comunitária. (GEDEON, 2006)

Segundo o documento de Educação em Direitos Humanos, Diretrizes Nacionais (2013), a educação é necessária para uma sociedade justa e ética, tendo como dever implantar uma tríplice finalidade educacional para os direitos humanos e para a paz: a informação, a formação e a transformação. Esta tríade poderá ser construída com os alunos de diversas maneiras, sendo a arte uma delas.

Desta forma é possível pensar que há uma imbricação necessária entre ética e direitos humanos, sendo a educação um eixo comum entre esses dois temas. Dessa 
forma, a educação é colocada como meio de discussão e aprofundamento ético e dos direitos humanos. No caso dos irmãos Naves, a ausência desse aprofundamento foi decisiva para as funestas consequências narradas por Person em seu filme.

\section{O caso dos irmãos Naves e a banalidade do mal: Uma perspectiva filosófica}

A filosofia ocidental, desde os pré-socráticos, sempre esteve profunda e radicalmente atrelada à vida dos homens. Inicialmente, fez-se uma abordagem mais cosmológica, como preconizaram Tales de Mileto, Anaxímenes, Heráclito e outros filósofos antes do século VI a.C. Posteriormente, no período clássico, outras preocupações passam a ser objeto da filosofia, a saber, a política, a educação e a ética, que passam a ser temas recorrentes em seus textos e falas, onde as figuras de Sócrates, Platão e Aristóteles marcam o cenário filosófico,

Desta forma, a influência da filosofia na história e nos acontecimentos, ora interpretando, ora problematizando, tornou-se comum e necessária. Segundo as palavras de Karl Jaspers: "O problema crucial é o seguinte: a filosofia aspira à verdade total, que o mundo não quer. A filosofia é, portanto, perturbadora da paz." (JASPERS, s/d, p.140)

A própria história da filosofia nos permite afirmar que nada escapa às "potentes lentes" da reflexão filosófica, uma vez que tudo pode ser objeto de sua análise. Neste sentido, a arte, mais propriamente a produção cinematográfica, também está profundamente relacionada com o pensar filosófico. A produção fílmica pode ser um meio para a filosofia como nos lembra Julio Cabrera e seu "conceito-imagem":

Direi que o cinema, visto filosoficamente, é a construção do que chamarei conceitos-imagem, um tipo de "conceito visual" estruturalmente diferente dos conceitos tradicionais utilizados pela filosofia escrita, a que chamarei aqui de conceitos-ideia. (CABRERA, 2006, p.20)

As produções cinematográficas, os roteiros, a fotografia, a direção, os atores e todo o aparato que compõe a que denominamos cinema, fornece ao espectador reflexivo a possibilidade de produzir análises ou aprofundar problemas filosóficos. Nesse sentido, é possível pensar que certos diretores são potencialmente mais filosóficos ou problematizadores, tais como Krzysztof Kieslowski, Andrei Tarkovsky, Ingmar Bergman e Ken Loach, que são diretores da contemporaneidade. Assim, é possível afirmar que o cinema, em seus diversos temas e gêneros, sendo comercial ou não, também pode produzir reflexões. Cada história ou roteiro carrega em si questões, 
posições e proposições oportunas para o pensamento filosófico, podendo estar presente numa grande produção de Hollywood, numa produção brasileira do Cinema Novo, ou até mesmo em um curta metragem. Assim, o cinema como linguagem está imbricado com a filosofia e a produção de conhecimento.

Da mesma forma acontece com a obra cinematográfica analisada neste artigo, que retrata uma situação real ocorrida na cidade de Araguari, Minas Gerais em 1937. Ainda que os fatos tenham sido chocantes, e que o caso tem sido considerado pela comunidade jurídica como um dos mais célebres erros judiciais da história brasileira, nossa análise se restringirá unicamente ao filme de Luiz Sérgio Person. A obra se notabiliza por seu forte realismo, com planos onde a violência sofrida pela família Naves é exposta de maneira brutal, impressionado ao público da época. O roteiro assinado por Person e Bernardet exprimem com radicalidade os eventos ocorridos, mas ainda não retratam verdadeiramente toda a crueldade e violência impostas aos Naves.

Como já enfatizado, o filme foi realizado em 1967, período de repressão da liberdade de expressão, exigindo energia e coragem de Person e seu companheiro de roteiro Jean Claude Bernardet, que assim afirma na "coleção aplauso cinema nacional" de 2004:

\begin{abstract}
Não sabíamos como a censura reagiria ao filme, de modo que eu fichava rigorosamente todas as informações, com suas fontes, referentes a cenas e diálogos com os quais a censura pudesse implicar. Nenhuma concessão foi feita, tudo o que achávamos que devia ser mostrado e dito entrou no filme. $\mathrm{Na}$ época que vivíamos, isso representava um risco. Em momento algum, Person fraquejou ou hesitou: realizar os Naves foi realmente um ato de coragem. (BERNARDET, 2004, p. 12).
\end{abstract}

Para uma melhor compreensão dos eventos narrados no filme faz-se necessária uma breve contextualização. A produção de Person data de 1967, retratando os eventos iniciados em 1937 em Araguari. Neste ano, Getúlio Vargas, então presidente do Brasil, estabelece um regime ditatorial, conhecido como Estado Novo, influenciando no andamento das investigações do caso envolvendo os irmãos Naves. Para trabalhar no caso, o governo federal nomea um delegado militar, tenente da força pública, Francisco Vieira dos Santos para a condução das investigações, figura tão importante quanto trágica, bem retratado por Person, na interpretação competentemente de Anselmo Duarte.

Os irmãos Joaquim Naves Rosa e Sebastião José Naves foram acusados, 
barbaramente torturados, presos e condenados ilegalmente em decorrência do desaparecimento de Benedito Pereira Caetano de posse de uma quantia de 90 contos de Réis. A acusação responsabilizava os irmãos Naves pelo assassinato de Benedito Pereira e posteriormente se estendeu a seus parentes próximos como a mãe de ambos, Ana Rosa Naves, às esposas e aos cunhados. Na fita de Person, notam-se questões reflexivas, que vão desde aspectos judiciais, à discussão sobre os direitos humanos e conflitos éticos, perspectiva essa que norteia o presente artigo.

Os fatos presentes no filme de Person, em especial, o tratamento dispensado pelo poder público aos irmãos Naves, nos permite uma reflexão sobre a relação entre a ética, o indivíduo e o Estado. Essa imbricação entre ética, cidadania e comunidade nos remete ao filósofo Aristóteles, lembrado aqui por Manfredo Araújo de Oliveira:

\begin{abstract}
O ético é, então, o que pertence ao "etos", ao mundo institucional da pólis. É exatamente esse etos que realiza o processo de universalização que efetiva o homem enquanto homem. Por essa razão, a determinação ética é essencialmente política, uma vez que a pólis é práxis que atualiza o ser potencial do homem. A pólis, nesse sentido, emerge para Aristóteles como a atualização da natureza do homem. (OLIVEIRA, 2003, p. 15, 16)
\end{abstract}

O pensamento aristotélico é uma verdadeira desconstrução daquilo que assistimos no filme de Person, visto que os irmãos Naves, ainda que pertençam a polis, não encontram lá qualquer resquício de um ethos que lhes possa garantir um tratamento adequado e legal.

Percebe-se aqui uma situação contrária daquela pensada pelo estagirita, uma vez que, no caso dos irmãos Naves, a moral vigente à época destoava da ética, cuja característica marcante é a universalidade, que nos remete a ideia de bem, lembrada por Vázquez:

O problema do que fazer em cada situação concreta é um problema práticomoral e não teórico-ético. Ao contrário, definir o que é o bom não é um problema moral cuja solução caiba ao indivíduo em cada caso particular, mas um problema geral de caráter teórico, de competência do investigador da moral, ou seja, do ético. (VÁZQUEZ, 1985, p. 7 e 8)

Nessa perspectiva, é possível pensar que Bernardet indica uma dimensão éticopolítica na elaboração do roteiro para além da simples exposição de um erro judiciário:

De volta a São Paulo, começamos a trabalhar no roteiro propriamente dito. Já nesta fase, tínhamos idéias mais claras sobre o filme. Já não se tratava apenas de relatar o "erro judicial" ocorrido no final dos anos 30 no interior de Minas Gerais. As relações com o nosso presente social e político eram evidentes: a polícia tinha inventado uma falsa realidade pela tortura, e a tortura vinha sendo praticado no Brasil pelo regime militar. O julgamento dos Naves se 


\begin{abstract}
deu no início do Estado Novo, com um judiciário submetido às novas autoridades, e no nosso presente a justiça tinha deixado de existir e se instalara um regime de violência $\mathrm{e}$ arbitrariedade. $\mathrm{O}$ filme seria absolutamente fiel aos fatos dos anos 30, mas se tornava uma metáfora política de nosso presente. Denunciaríamos a tortura e a arbitrariedade. Durante toda a elaboração do filme, nunca se perdeu de vista essa perspectiva, a tal ponto que passamos a qualificar os Naves de "filme Castelo Branco", em oposição ao roteiro que escreveríamos em seguida, A Hora dos Ruminantes, que chamávamos de "filme Costa e Silva". (BERNARDET, 2004 , p. 8 e 9)
\end{abstract}

É possível pensar que o contexto histórico, político e social brasileiro na primeira metade do século XX e sua moral vigente à época dos fatos certamente influiu no tratamento reducionista e preconceituoso dispensado à família Naves. Para além dessa importante perspectiva ética presente, o filme nos convida a refletir sobre a possível incapacidade de agir com a racionalidade necessária por parte dos agentes públicos responsáveis pelas investigações no caso envolvendo os irmãos Naves. A força policial em Araguari e suas funestas ações indicam indivíduos plenamente convencidos de estarem praticando um mero e burocrático dever funcional. Desta forma, é possível pensar que um dos mais notórios erros judiciais no Brasil possa ter ocorrido devido à estéril crença no dever funcional, sem qualquer capacidade reflexiva e crítica por parte dos agentes públicos responsáveis por torturas e arbitrariedades de toda sorte à família Naves.

Assim, não se trata de um caso de crueldade consciente objetivando uma confissão, mas algo mais perturbador e perigoso, a saber, a violência e o completo desrespeito à dignidade humana oriunda de agentes públicos que destituídos de qualquer capacidade de reflexão, limitam-se a cumprir ordens ou metas. Esse cenário onde o indivíduo é esmagado dentro de uma espiral cuidadosamente preparada pelo poder público, bem ao estilo dos personagens trazidos por Kafka, mas que dialeticamente são regidos pela inteira incapacidade de reflexão ética, a exemplo daquilo que nos é mostrado no filme de Person, nos remete à reflexão produzida por Hannah Arendt, quando escreveu sobre o julgamento de Eichmann em Jerusalém.

Nesses contextos totalitários, a moral vigente amparada por uma nova ordem jurídica e política, pode reproduzir aquilo que Arendt denominou como a banalidade do mal, ou seja, os detentores do poder e seus prepostos podem agir de maneira cruel ao cumprir ordens ou juramentos, sem qualquer ação crítica, reflexiva ou ética, como se 
deu com Eichamann e sua participação no extermínio de judeus durante a segunda guerra mundial.

Parece apropriado pensar que a reflexão de Hannah Arendt sobre a banalidade do mal pode ser útil na compreensão dos eventos envolvendo os irmãos Naves e a força policial responsável pela apuração dos fatos, vividamente mostrados no filme de Person.

Por força de todo o tratamento brutal dispensado à família Naves somos levados a pensar que os agentes polícias se assemelham a seres monstruosos. Contudo, dentro de uma perspectiva mais crítica, podemos pensar como Arendt, quando analisa Eichmann, alertando que burocratas ordinários podem ser mais perigosos do que qualquer monstro mitológico quando incapazes de questionar uma ordem ou pensar criticamente. Segundo Arendt (2013, p.67), “[...] apesar de todos os esforços da promotoria, todo mundo percebia que esse homem não era um "monstro", mas era difícil não desconfiar que fosse um palhaço".

Os sistemas totalitários podem potencializar a banalidade do mal de que trata Arendt, porém tal fenômeno está sempre rondando a sociedade, independente do contexto político e social vigente. A obra de Arendt, como chave de compreensão do filme de Person, nos permite dialogar com o tema da ética, do totalitarismo, da banalidade do mal, bem como os direitos humanos. Nesse sentido é oportuna a citação de Celso Lafer acerca do futuro da dignidade humana:

São reais os riscos de reconstituição de um " estado totalitário de natureza" cuja emergência configurou a ruptura, com a qual Hannah Arendt, enquanto ouriço, preocupou-se centripetamente, e à qual ela reagiu como raposa, afirmando a importância, para a dignidade humana, do pluralismo centrífugo de um mundo assinalado pela diversidade e pela liberdade. Com efeito, continuam a persistir no mundo contemporâneo situações sociais, políticas e econômicas que contribuem para tornar os homens supérfluos e sem lugar num mundo comum. (LAFER, 1999, p. 15).

Desta forma, "O caso dos irmãos Naves" e o pensamento de Hannah Arendt podem se converter numa poderosa advertência não apenas sobre a violência de Estado, mas também a banalidade do mal, fruto da total irreflexão. Desgraçadamente, esse fenômeno se repetiu em diversos outros momentos no Brasil e no mundo após 1937, o que nos permite pensar sobre a atualidade do filme de Person e do pensamento de Hannah Arendt.

\section{Considerações finais}


Para além da ação docente, o próprio ato de ensino e aprendizagem se consolida de diversas maneiras e recursos possíveis. Dentre as possibilidades disponíveis ao professor, o recurso fílmico, com toda a sua riqueza e diversidade, pode propiciar ao educando uma verdadeira "janela" ao mundo, uma vez que o cinema dialoga com os mais variados ramos do saber.

Temas com perspectivas densas e complexas podem ser problematizados com sucesso por meio desse recurso. Nesse sentido, o filme $\mathbf{O}$ caso dos irmãos Naves, de Luiz Sérgio Person, numa análise crítica, permite problematizar temas relacionados a filosofia moral, direitos humanos e a banalidade do mal, como pensada por Hannah Arendt.

A imbricação entre a ética e a produção fílmica é marcante, pois se a primeira se relaciona com o comportamento humano, a segunda o retrata vividamente nas telas. Assim, é possível afirmar que os filmes cumprem um importante papel ao problematizar questões éticas em seus roteiros, dentre outros muitos temas.

Por sua complexidade e realismo, o filme $\mathbf{O}$ caso dos irmãos Naves nos permite um olhar multidimensional. Contudo, no presente artigo objetivamos fazer um recorte em apenas dois temas específicos: os aspectos éticos latu sensu e a identificação da banalidade do mal como possível justificativa da ação dos agentes públicos que conduziram a funesta investigação, tendo como norte um eixo comum, a saber, o recurso fílmico como meio eficaz e crítico no processo ensino e aprendizagem.

Por fim, tanto o pensamento de Hannah Arendt quanto o filme de Person nos indicam que a irreflexão ética pode atingir tanto seis milhões de judeus na Europa do século XX, bem como dois humildes irmãos no interior de Minas Gerais.

Submetido em janeiro de 2018. Aprovado em abril de 2018.

\section{Referências}

ARENDT, Hannah. Eichmmam em Jerusalém. Tradução José Rubens de Siqueira. São Paulo: Companhia das Letras, 1999.

BERNARDET, Jean-Claude. O caso dos irmãos naves: chifre em cabeça de cavalo. São Paulo: Imprensa Oficial do Estado de São Paulo: Cultura - Fundação Padre 
Anchieta, 2004.

. O que é cinema. São Paulo: Brasiliense, 2004.

BRASIL. Constituição (1988). Constituição da República Federativa do Brasil. Brasília, DF: Senado Federal: Centro Gráfico, 1988. (Artigo 205).

BRASIL. Lei de Diretrizes e Bases da Educação Nacional: Lei no 9.394, de 20 de dezembro de 1996. Brasília: Câmara dos Deputados, edições Câmara, 2015. Artigo 26 $\S 8$.

BRASIL. Educação em Direitos Humanos: Diretrizes Nacionais - Brasília: Coordenação Geral de Educação em Sdh/Pr, Direitos Humanos, Secretaria Nacional de Promoção e Defesa dos Direitos Humanos, 2013.

CABINE CULTURAL. Ética no cinema: Lista de filmes que abordam questões éticas e morais. Disponível em: < http://cabinecultural.com/2015/04/04/a-etica-nocinema-lista-de-filmes-que-abordam-questoes-eticas-e-morais/>. Acesso em: 20 de jan. 2018.

CABRERA, Julio. O cinema pensa: uma introdução à filosofia através dos filmes; tradução de Ryta Vinagre. Rio de Janeiro: Rocco, 2006.

CARNEIRO, Alfredo. Cinema, ética, dominação e liberdade. Disponível em: http://www.netmundi.org/home/2016/cinema-etica-dominacao-e-liberdade/. Acesso em: 04 fev. 2018.

CARVAlHO. Maria do Socorro. Cinema novo brasileiro. In: História do cinema mundial (livro eletrônico). Fernando Mascarello (org.). $1^{\text {a }}$ edição. Campinas, SP: Papirus, 2014

CHRISTOFOLETTI, Rogério. Ética e cinema: Notas sobre uma experiência didática. Comunicação \& Educação. São Paulo, 2003.

CORTINA, Adela; Martinez, Emilio. Ética. São Paulo: Ed. Loyola, 2005.

FERREIRA, Aurélio Buarque de Holanda. Mini Aurélio: O dicionário da língua portuguesa. Coordenação de edição Marina Baird Ferreira. - 8. Ed. - Curitiba: Positivo, 2010.

GEDEON, Leonardo. Educação como um ato político (ao Mestre Paulo Freire). Disponível em: https://www.recantodasletras.com.br/artigos/165942. Acesso em: 04 fev. 2018.

IRWIN, W, et al. Os Simpsons e a filosofia - O D’oh! De Homer. São Paulo: Madras, 2004.

JASPERS, Karl. Introdução ao pensamento filosófico: tradução de Leonidas Hegenberg e Octanny Silveira da Mota . São Paulo: Editora Cultrix, s/d. 
KARNAL, Leandro. Leandro Karnal - Você gosta de cinema?. Disponível em: <https://www.youtube.com/watch?v=IdNuElE-GLA>. Acesso em: 04 fev. 2018.

KARNAL, Leandro. Conversas com um jovem professor. São Paulo: Contexto, 2017.

LAFER, Celso. A reconstrução dos direitos humanos: um diálogo com o pensamento de Hannah Arendt. São Paulo, Companhia das Letras, 1999.

OLIVEIRA, Manfredo Araújo de. Ética e sociabilidade. São Paulo: Loyola, 2003.

ORICCHIO. Luiz Zanin. Cinema brasileiro contemporâneo (1990 - 2007). In: O cinema mundial contemporâneo (livro eletrônico). Mauro Baptista e Fernando Mascarello (organizadores).. Campinas, SP: Papirus, 2016.

POURRIOL, Ollivier. Cinefilô: As mais belas questões da filosofia no cinema. Tradução: André Telles - Rio de Janeiro: Jorge Zahar Ed., 2009.

REINA, A. Cinema e filosofia: ensinar e aprender filosofia com os filmes. Curitiba: Juruá, 2016.

SANTOS, Ivone Aparecida dos. Educação Para a Diversidade: Uma prática a ser construída na Educação Básica. Universidade Estadual do Norte do Paraná - Campus de Cornélio Procópio-Paraná, 2008.

de Educação. Universidade Estadual de Campinas, Faculdade de Educação. Revista Brasileira de educação v. 15 n. 44, 2010.

VALLS, Álvaro. O que é ética? [s.I]: Editora Brasiliense, 1994. (Coleção Primeiros Passos $-\mathrm{N}^{\mathrm{o}}$ 177).

VÁSQUEZ. Adolfo Sánchez. Ética. Rio de Janeiro: Editora Civilização Brasileira, 1985.

XAVIER, Maurício. Você se lembra de Luis Sérgio Person? Disponível em: https://vejasp.abril.com.br/cidades/luiz-sergio-person-cinema/. Acesso em: $24 \mathrm{de}$ setembro de 2017. 